\title{
Asbab an-Nuzul dalam Kitab Tafsir al-Misbah Karya M. Quraish Shihab
}

\author{
Risqo Faridatul Ulya \\ Universitas Islam Negeri \\ Sunan Kalijaga \\ D.I. Yogyakarta, Indonesia \\ E-mail: \\ risqoulya96@gmail.com
}

\begin{abstract}
Abstrak: Tulisan ini membahas mengenai asbab an-Nuzul dalam tafsir al-Misbah dalam surat al-Baqarah. Asbab an-Nuzul merupakan peristiwa yang melatarbelakangi turunnya ayat-ayat Alquran. Baik itu berupa pertanyaan, pernyataan atau jawaban dari suatu hukum kejadian yang timbul dari kejadian tersebut. Metode yang diterapkan dalam tulisan ini adalah metode analisis-deskriptif. Tujuan dari tulisan ini akan mengungkap pengertian asbab anNuzul, biografi M. Quraish Shihab, sekilas kitab tafsir al-Misbah, seberapa banyak asbab Nuzul dalam tafsir al-Misbah, dan kegunaan asbab Nuzul. Hasil penelitian ini bahwa asbab an-Nuzul dalam kitab tafsir al-Misbah terdapat sebanyak 7 ayat dalam surat alBaqarah yang berjumlah 286 ayat. Dalam kitab tafsir al-Misbah M. Quraish Shihab tidak memberikan secara detail mengenai asbab anNuzul di kitabnya. Karena ayat- ayat Alquran yang turun dan sampai kepada Nabi Muhammad Saw. tidak sepenuhnya ada kausalitas dalam ayat tersebut. M. Quraish Shihab lebih menekankan penafsirannya dengan pendekatan bahasa, dan setiap tulisan maupun tafsir penulis pasti memiliki batasan atau fokus kajian dalam menafsirkan Alquran agar dapat mencapai sasaran yang diinginkan oleh penulis dengan cara melihat situasi dan kondisi ketika dia menafsirkan Alquran, yakni kitab tafsir Misbah.
\end{abstract}

\begin{abstract}
This paper discusses the asbab of an-Nuzul in the interpretation of al-Misbah in the letter al-Baqarah. Asbab anNuzul is the background for the revelation of the verses of the Koran. Whether it is in the form of a question, statement or answer from an incident law arising from the incident. The method applied in this paper is a descriptive analysis method. The purpose of this paper is to reveal the meaning of an-Nuzul asbab, a biography, a glimpse of the interpretation of the book al-Misbah, how many asan-Nuzul asbab in the interpretation of al-Misbah, and the use of Nuzul asbab in the interpretation of al-Misbah. The result of this research is the asbab an-Nuzul in the tafsir al-Misbah book, there are 7 verses in the al-Baqarah that can contain 286 verses. In the commentary book al-Misbah M. Quraish Shihab does not provide details about the asbab an-Nuzul in his commentary book. Because each verse in the Koran that came down and reached the Prophet Muhammad. there is no causality in the verse. And M. Quraish Shihab also emphasizes his interpretation with a language approach, and in every writing and interpretation the writer must have a limitation or focus of study in interpreting the Koran in order to achieve the goals desired by the author by looking at the situation and conditions. when he interprets the Koran, the Misbah commentary book.
\end{abstract}

Kata Kunci: Asbab an-Nuzul, al-Misbah, al-Baqarah.

\section{PENDAHULUAN}

Asbab an-Nuzul merupakan
Alquran dan menjadi bagian dari ilmu

ulumul Quran. Ada beberapa kelompok kecil ilmuan muslim yang tidak 
memandang pentingnya ilmu asbab melihat apakah dengan surat terpanjang nuzul dalam menafsirkan Alquran. ini M. Quraish Shihab banyak Tanpa asbab an-Nuzul, kata mereka, mencantumkan asbab an-Nuzul. tidak ada halangan dalam menafsirkan Tujuan tulisan ini adalah untuk Alquran. Dengan kalimat lain, menambah wawasan agar ilmu-ilmu seseorang dimungkin menafsirkan yang telah ada sebelumnya dapat Alquran tanpa harus melengkapi dikembangkan, dipahami dan dirinya dengan ilmu Asbab an-Nuzul diaplikasikan dan menjadi ibrah dalam (Suma, 2013:203). Misalnya khalifah kehidupan serta untuk mengecek 'Utsman bin Mazd'un dan Marwan bin seberapa banyak asbab an-Nuzul dalam Hakam pernah keliru dalam memahami tafsir al-Misbah. Maka dari itu peneliti ayat-ayat al-Qur'an dikarenakan tidak tertarik untuk membahas tema menguasai asbab an-Nuzul. (Syafril, mengenai asbab an-Nuzul dalam kitab 2018: 26).

tafsir al-Misbah (Studi terhadap Surah

Seorang ulama bernama al-Wahidi mengatakan ilmu asbab an-Nuzul itu sangat dipentingkan dalam menafsirkan al-Qur'an untuk mengetahui segi makna, kisah, dan sebab turunnya ayat tersebut. (al-Wahidi, 1988: 4).

Dalam penelitian ini, peneliti berusaha untuk menelisik seberapa banyak asbab an-Nuzul dalam kitab tafsir al-Misbah yang beliau cantumkan dalam surah al-Baqarah. Sedangkan mengenai pemilihan surah peneliti memilih surat al-Baqarah dengan alasan surat al-Baqarah dikarenakan surat ini terdapat muatan ayat yang paling terbanyak dari 113 surat dalam al-Qur'an dari sini peneliti ingin al-Baqarah).

\section{METODE PENELITIAN}

Penelitian ini adalah penelitian kepustakaan dengan menerapkan metode deskriptif-analisis dan tujuan agar dapat menganalisis Asbab anNuzul dalam kitab tafsir al-Misbah, terutama Surat Al-Baqarah. Terkait dengan sumber data dalam penelitian ini yakni sumber data primer dan sumber data sekunder yang terkait dengan tema penelitian.

\section{HASIL DAN PEMBAHASAN}

\section{Asbabal-Nuzul}

Definisi Asbaban-Nuzul 
Secara etimologi, kata (أسباب) yang berarti sebab, bentuk jama' (plural) dari kata mufrad (tunggal), sabab (سبب) secara bahasa artinya alasan, sebab, illat (dasar logis), pendorong, perantara, tali kehidupan, hubungan kekeluargaan, wasilah, jalan, persahabatan, asal, kerabat, dan sumber. Kata sabab diartikan tali dan dapat menghubungkan kepada air. Selanjutnya lama kelamaan dapat digunakan dalam pengertian segala sesuatu yang bisa dikoneksikan pada yang lain. (Ya'qub, 1425: 43). Dalam kamus al-ma'aniy kata sabab diartikan sebab, alasan, motif, sarana, dan perantara. Sedangkan kata (نزول) terambil dari kata نزل yang mempunyai tiga huruf $J$-j-j dan kemudian dibentuk sekitar 299 kata dengan berbagai derivasinya. (al-Baqi, 1986: 694-698). Sehingga mempunyai arti turun, datang, dan terjadi. Nuzul yang dimaksud di sini adalah penurunan Alquran dari Allah Swt. kepada Rasulullah Saw. melalui perantara malaikat Jibril. (Suma, 2013: 204).

Secara terminologi al-Suyuti berpendapat asbab an-Nuzul tidak dapat dipahami sebagai sebab yang mengakibatkan ayat itu turun dikarenakan turunnya ayat bukan adanya kausalitas. (al-Suyuti, 1996: $85)$.

Sedangkan menurut M. Quraish Shihab, beliau mendefinisikan asbab nuzul Alquran dengan cara memilih peristiwanya, dan menyatakan bahwa kejadian yang menyebabkan turunnya suatu ayat, di mana ayat tersebut menjelaskan pandangan Alquran ataupun mengomentari pengertiannya, menjelaskan hukum dari suatu peristiwa tersebut (Baidan, 2011:135).

\section{Redaksi Asbab an-Nuzul}

Redaksi yang menjelaskan mengenai asbab an-Nuzul biasanya ada yang bentuk sebuah peryataan tegas atau jelas (sarih) mengenai sebab, ada juga pernyataan yang mengandung kemungkinan (muhtamil). Bentuk redaksi yang jelas ialah apabila rawi menuturkan: "sebab turun ayat ini ialah..." atau menggunakan $f a$ ta'qibiyah "maka turunlah ayat" atau juga menggunakan redaksi: سئل رسول الله صلّى الله عليه وسلّم أنكذا فنزلت الأية (suila rasulullahishallallahu'alaihiwasallama 'ankadza fanazalat al-ayayatu) "Rasulullah ditanya tentang hal ini, maka turunlah ayat ini". Pernyataan 
dari dua bentuk di atas merupakan pernyataan yang jelas mengenai sebab.

نزلت هذه الآية في كذا: Terdapat redaksi “Ayat ini turun mengenai ini..." redaksi di atas menerangkan sebab nuzul dan menjelaskan tentang kandungan ayat mengenai hukum. Ibn Taimiyyah berkata: perkataan mereka bahwa ayat ini turun berkenaan perkara ini..., dimaksud penjelas tentang asbabun nuzul, ada kalanya pula difokuskan ke suatu ayat meskipun tidak terdapat asbabun nuzulnya. Banyak ulama berbeda asumsi tentang perkataan sahabat ini: "Ayat ini turun berkenaan perkara ini..." terdapat pertanyaan apakah perkataan ini termasuk ke dalam hadis muttasil misalnya jika ia menyatakan asbab suatu ayat yang dinuzulkan atau berlaku sebagai tafsir dari pada sahabat itu sendiri dan bukan muttasil? Imam al-Bukhari menilainya hadis muttasil sedangkan yang lainnya tidak menilai. Beberapa hadis muttasil menurut etimologi ataupun terminologi, semacam kitab hadis anNasa'i dan kitab lainya. Lain kondisinya jika sahabat mengatakan suatu asbab yang setelahnya diturunkan ayat tersebut. Maka, mereka mencantumkan penjelasan tersebut kedalam hadis muttasil. Di dalam kitab al-Burhan Zarkasyi menerangkan: Dapat dilihat melalui kelaziman para sahabat dan tabi'in apabila salah sorang dari mereka mengatakan: "Ayat ini turun berkenaan perkara ini..."dengan maksud ayat ini mengenai perkara suatu hukum dan bukan perkara mengenai turunnya ayat tersebut. Penjelasan di atas memberikan kesimpulan suatu hukum dan bukan merupakan pemberitahuan peristiwa yang terjadi (al-Qattan, 2013: 120123).

Ada redaksi yang menyatakan: "saya menyangka ayat ini diturunkan mengenai dengan..." atau "saya tidak mengira sebenarnya ayat tersebut turun melainkan bertepatan dengan...”. Dalam redaksi di atas mengandung dua kemungkinan, yakni menjadi sebab atau bukan menjadi sebab-nya (Suryadi, 2013: 117-118).

\section{Trik Memafhumi Asbabun Nuzul}

Pegangan mayoritas ulama mengenai asbabunnuzul adalah riwayat shahih dengan bersumber kepada Nabi Saw. ataupun sahabat. 
Terdapat beberapa opsi para ulama dalam menentukan riwayat-riwayat yang diterima sebagai penjelas sebab asbab an-Nuzul yakni pertama, memilih riwayat-riwayat yang berkualitas shahih. Kedua, jika terdapat riwayat-riwayat yang ternilai shahih, tugas selanjutnya adalah melakukan tarjih. Dan apabila riwayat-riwayat tersebut kurang lebih sama shahihnya, dan dimungkinkan untuk ditarjih, dijadikan pegangan adalah yang rajih dan meninggalkan yang marjuh. Ketiga, jika di antara riwayat-riwayat itu sama-sama bernilai shahih dan tidak dapat ditarjih, jalan yang ditempuh dengan cara dikompromikan, maka riwayat itu sama-sama digunakan dan saling menjelaskan. Keempat, apabila kedua riwayat sama-sama terbilang shahih, sulit untuk ditarjih dan dikompomikan, maka kedua riwayat dapat dipakai, dengan pengertian bahwa ayat tersebut turun secara berulang-ulang (Muslimah, 2017: 47).

\section{Biografi Shihab}

Nama lengkapnya adalah Muhammad Quraish Shihab. Beliau dilahirkan di Rappang, Sulawesi Selatan, 16 Februari pada tahun 1944.
Ayahnya bernama Abdurrahman Shihab (1905-1986) beliau seorang guru besar dalam bidang ilmu tafsir dan dipandang sebagai tokoh pendidik di Sulawesi Selatan. Ayahnya termasuk pendiri UMI dan Institute Agama Islam Negeri Alauddin Makasar di Ujung Pandang dan tercatat sebagai mantan rektor pada kedua perguruan tinggi: UMI 1959-1965 dan IAIN 1972-1977.

M. Quraish Shihab memulai pendidikannya pada SD Muhammadiyah yang terletak di kampung halamannya Ujung Pandang, setelah itu melanjutkan jenjang pendidikannya ke SMP Muhammadiyah, Malang, dengan sambilan menyantri di Ponpes darul alhadis al-fiqiyyah bertujuan untuk mendalami studi keislamannya, pada tahun 1958, M. Quraish Shihab pergi ke Kairo Mesir untuk menuntaskan pendidikannya di kelas II Tsanawiyyah al-Azhar. Tahun 1967 M. Quraish Shihab meraih gelar licence pada Fakultas Ushuluddin prodi Tafsir Hadis Universitas al-Azhar. Setelah itu, beliau meneruskan pendidikannya dengan prodi dan fakultas yang sama. Tahun 1969 beliau mendapatkan gelar MA dengan tesisnya yang berjudul al- 
I'jaz al-Tasyri ilial-Qur'an al-Karim (Saragih, 2015: 89-91). Kemudian tahun 1980, beliau merajut pendidikannya lagi di Universitas alAzhar dan menulis disertasi yang berjudul Nazam al-Durar li al-Biqa" $i$ : Tahqiq wa Dirasah. Pada tahun 1982, beliau sukses meraih gelar doktor dalam studi ilmu-ilmu Alquran dan yudisium Summa Cumlaude bersamaan dengan penghargaan Mumtaz Ma'aMartabatal-Syaraf al-Ula

(Wartini, 2014:116).

Adapun karya-karya M. Qurasih Shihab ialah: Kitab Tafsir Al-Misbah: Kesan, Pesan, dan Keserasian AlQuran (2000), Wawasan al-Qur`an Tafsir Maudu'i atas pelbagai Persoalan Umat (1995), Membumikan AlQur`an: Fungsi dan Peran Wahyu dalam Kehidupan Masyarakat (1992), Tafsir Al-Mannar: Keistimewaan dan Kelemahannya (1984), Lentera Hati: Kisah dan Hikmah Kehidupan (1994), dan sederetan karya-karya lainnya (Ghofur, 2013:187).

\section{Sekilas Tentang Kitab Tafsir Al- Misbah}

Di antara karya- karya Muhammad Quraish Shihab yang paling popular yaitu kitab tafsir al-Misbah. Kitab tafsir
al-Misbah ditulis Muhammad Quraish Shihab di Kairo, Mesir pada tahun $1420 \mathrm{H}$. Beliau menyelesaikannya di Jakarta pada tanggal 8 Rajab $1432 \mathrm{H}$ (Rohani, 2018: 31). Nama lengkap karya ini berjudul: Tafsir al-Misbah: Pesan, Kesan dan Keserasian alQur'an. Kitab tafsir ini diberi singkatan tafsir al-Misbah yang artinya lampu, pelita, dan lentera dengan fungsi memberikan penerangan kepada siapa saja yang masih berada dalam suasana kekelamaan. Pemberian nama pada kitab ini, beliau berharap supaya karya tulisnya dijadikan sebagai cahaya untuk mencari petunjuk dan pedoman di dalam kehidupan (Tamam, 2008: 3738).

Kata "Pesan" terdapat makna Alquran yakni firman-Nya yang berisikan hudan kepada setiap makhluknya. Kata "Kesan" bermaknakan kutipan-kutipan berbagai macam tafsir para ulama. Sedangkan kata "Keserasian" ialah munasabah dan satu surah ke surah lainnya (berkaitan) (Nur, 2018:3).

Metode yang digunakan dalam kitabtafsir al-Misbah yaitu kombinasi dari beberapa metode seperti metode tahlili, metode muqarran dan metode 
maudhu'i. Sedangkan bentuk yang digunakan dalam kitab tafsir al-Misbah yakni termasuk bentuk tafsir bi al-ra'yi dikarenakan terdapat argumen akal disamping hadis-hadis nabi. Serta corak penafsirannya adalah adab ijtima’ $i$ (Anshori, 2006: 51-52).

Klasifikasi Asbab an-Nuzul dalam Surah al-Baqarah karya Imam Jalaluddin as-Suyuthi dan Imam Abi Hasan 'Ali bin Ahmad Al-Wahidi

Adapun asbab an-Nuzul dalam kitabnya Imam Jalaluddin as-Suyuthi pada surah al-Baqarah [2]antara lain: 6, 14, 19, 26, 44, 62, 76, 79, 80, 89, 94, 97, 99-100, 102, 104, 106, 108, 113, $114,115,118,119,120,125,130,135$, 142-144, 154, 158, 159, 164, 170, 174, 177, 178, 184, 186, 187, 188, 189, 190A. 194, 195, 196, 197, 198, 199, 200, 204, 207, 208, 214, 215, 217, 219, 221, 222 , 223, 228, 229, 229, 230, 231, 232, 238, 240, 241, 245, 256, 257, 267, 272, 274, 278, 285 (as-Suyuthi, 11-52 \& Hayyie, 2008: 25-114).

Selanjutnya klasifikasi Imam Abi Hasan 'Ali bin Ahmad Al-Wahidi dalam surah al-Baqarah [2] di antaranya: $1 \& 2,6,14,21,26,44,45$, $62,79,80,75,89,97,98,99,102,104$, 105, 106, 108, 109, 112, 114, 115, 116,
119, 120, 121, 133, 135, 138, 142, 143, 144, 146, 154, 158, 159, 164, 168, 174, 177, 178, 187, 188, 189, 189, 190, 194, 195, 196, 197, 198, 199, 200, 204, 207. 208, 214, 215, 217, 219, 220, 221, 222 , 223, 224, 226, 229, 232, 240, 256, 260 , 262, 267, 271, 272, 274, 278, 280, 285 (al-Wahidi, 24-98).

Tujuan pengklasifikasian kedua kitab di atas yakni kitab asbab anNuzul karya Imam Jalaluddin asSuyuthi dan karya Imam al-Wahidi untuk mengetahui berapa banyak asbab an-Nuzul dalam surah al-Baqarah dan untuk mengetahui berapa ayat $\mathrm{M}$. Quraish Shihab merujuk asbab anNuzul pada kedua kitab ini.

\section{Asbab an-Nuzul dalam Kitab Tafsir al-Misbah}

Tipologi Penyajian Asbab an-Nuzul

Adapun klasifikasi asbab an-Nuzul karangan M. Quraish Shihab sebagai berikut:

Surah al-Baqarah [2] ayat 14

Asbab an-Nuzul ayat ini adalah Al-Khazin menyampaikan bahwa ayat ini turun mencamkan perilaku 'Abdullah Ibn Ubayy yang memberikan pujian kepada Abu Bakar, Umar bin Khatab dan Ali bin Abi Thalib r.a. tatkala dia ditegurkan 
supaya janganlah bermuka dua dia mengatakan: "Saya tidak mengatakan apapun terkecuali berkenaan dengan keyakinan bersama”. Setelah terpisah, 'Abdullah bin Ubayy mengatakan kepada teman-teman

sekemunafikannya, "Perbuatlah sebagaimana yang aku perbuat kepada orang-orang muslim" (Shihab, 2012: 130-131).

Sedangkan asbab an-Nuzul dalam kitabnya Imam Jalaluddin as-Suyuthi: al-Wahidi dan ats-Tsa'labi meriwayatkan dari jalur Muhammad bin Marwan dan as-Suddi dari alKalabi dari Abu Shaleh dari Ibnu Abbas, ia mengatakan bahwa "Ayat ini turun kepada Abdullah bin Ubay dan teman-temannya. Suatu ketika mereka berjumpa dengan para sahabat Nabi, kemdian ia mengatakan pada temantemannya. Saksikanlah cara saya menghindarkan orang-orang bambung itu dari kalian. Ia pun menghampiri Abu Bakr dan menjabat tangnnya, kemudian dia mengatakan, Selamat datang wahai Abu Bakar, yang akan menjadi pengganti berikutnya setelah Nabi, tatkala itu yang berada di gua dan memberikan segala harta dan jiwanya kepada Nabi Saw, kemudiann ia menggenggam tangan Umar dan mengatakan, selamat datang tuan Bani Adi bin Ka'ab, al-Faruq yang kukuh pada tali ajaran Islam. Dan memberikan segala harta serta jiwanya kepada Nabi kemudian, ia menggenggam tangan 'Ali dan mengatakan, Selamat datang anak paman Nabi sekaligus menantu Rasulullah Saw. kemudian sahabat Nabi pun pergi ke arah yang ingin dituju.

Kemudian Abdullah bin Ubay datang menjumpai handai-handainya dan mengatakan, bagaimanakah pendapat kalian tentang perbuatanku tadi? Jadi apabila kalian bertemu dengan mereka lakukanlah seperti apa yang saya lakukan tadi. Temantemannyapun memberikan pujian terhadap perbuatan Ubay. Lalu kaum muslimin mendatangi Rasulullah dan memberitahukan kepada Rasulullah mengenai Ubay, maka turunlah ayat ini" (as-Suyuthi, 11-52 \& Hayyie, 26).

Surah al-Baqarah [2]: 44

Dalam sebuah riwayat dipaparkan bahwa orang-orang Yahudi memerintahkan kerabatnya yang memeluk agama Islam supaya tetap 
memegang teguh kepercayaannya dan meneladani Rasulullah kepada mereka ayat ini turun (Shihab, 2012: 218). Dijelaskan dalam kitab asbab an-Nuzul karangan Imam al-Wahidi disebutkan bahwa:

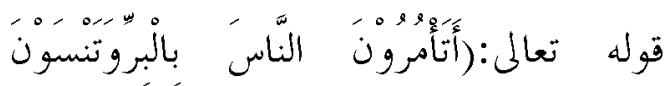

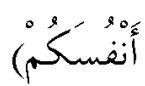
قال ابن عباس في رواية الكبي، عن أبي صالخ بالإ سناد الذي ذكر: نزلت في يهود [أهل] المدينة، كان الرجل منهم يقول لصهره ولذوي قرا بته ولمن بينهم وبينه رضاع من المسلمين: اثبت على الذي أنت عليه، وما يأمرك به هن وندا الرجل - يعنون محمدا - فإن أمره حق. فكانوا يأمرون الناس بذلك ولا يفعلو ئهو

Berkata Ibnu Abbas diriwayatkan dari Abi Shalih ayat ini turun kepada Yahudi Madinah salah seorang lakilaki di antara mereka itu ada yang berkata kepada mertuanya, kerabatnya dan orang muslim yang masih memiliki hubungan persusuan dengannya dia berkata teaplah pada agamamu dan apa yang diperintahkan Nabi kepadamu adalah benar. Mereka memerintahkan kepada ornag-orang untuk mengikuti nabi tetapi mereka sendiri tidak melakukannya. Sedangkan riwayat yang bersumber dari imam Jalaluddin as-Suyuthi pada ayat ini adalah al-
Wahidi dan ats-Tsa'labi menceritakan dari jalur Kalbi dari Abu Shaleh dari Ibnu Abbas mengatakan, "Ayat ini turun untuk orang-orang Yahudi Madinah. Seseorang dari mereka mengatakan pada kerabatnya, 'berpegang teguhlah kepada agama kalian dan ikutilah semua yang diinstruksikan Nabi, karena apa yang diperhatikannya terdapat sebuah kebenaran". Tatkala, orang-orang Yahudi telah lazim menyarankan perkara tersebut pada kerabatnya, tetapi mereka sendirilah yang lalai dan tidak melaksanakannya (al-Wahidi: 27).

Dari riwayat di atas, yang telah dipaparkan rujukan kitab asbab Nuzul Imam Jalaluddin dan al-Wahidi berbeda dari sanadnya, dengan konten yang sama dan jalur yang merujuk kepada sahabat yakni Ibnu Abbas. M. Quraish Shihabtidak memaparkan sanadnya seperti Jalaluddin dan alWahidi, akan tetapi beliau hanya menyebutkan matan, kemudian hanya memberikan esensi dari sebab turunnya ayat tersebut.

Surah al-Baqarah [2]: 114

Adanya riwayat yang disandarkan kepada Ibn 'Abbas bahwa ayat ini 
turun bersangkutan mengenai usaha kaum musyrik Mekkah yang menghalang-halangi kaum mukmin mendatangi kota Mekkah dan bertawaf di masjid al-Haram. Riwayat ini cukup beralasan dengan demikian dapatlah dikatakan bahwa, ayat-ayat yang lalu menguraikan kecaman kepada orangorang Yahudi, sekarang kecaman itu telah berpindah kepada kaum musyrik di Mekkah, ayat sebelumnya telah menyamakan kaum musyrik dengan Ahl al-Kitab dan mengaku diri dan golonganya yang memegang kebenaran dan menjastifikasi kelompok lainnya adalah kelompok yang membelok dan tidak mempunyai pondasi (Shihab, 2012: 359).

Asbab an-Nuzul as-Suyuthi: Ibnu Ahi Hatim meriwayatkan dari jalur Sa'id atau Ikrimah dari Ibnu Abbas bahwa kaum Quraish tidak membolehkan Nabi untuk melaksanakan shalat di ka'bah. Ibnu Jarir menceritatkan dari Ibnu Zaid, ia mengatakan: ayat di atas turun berkenaan dengan kaum musyrikin dikala itu Nabi tidak diperbolehkan untuk mendatangi Mekkah pada masa Hudaibiyyah (as-Suyuthi, 11-52 \& Hayyie, 2008: 47-48).
Dalam riwayat ini M. Quraish Shihab memaparkan matan saja sekaligus sanad yang dinisbatkan kepada sahabat yakni Ibnu Abbas.

Surah al-Baqarah [2]: 144

Ayat ini turun ketika Nabi Saw. berada di sebuah pondok yang dapat ditempati terletak di Madinah, dikenal dengan masjid Bani Salamah sehigga di mana saja kamu berada, walaupun ayat ini bukan turun di rumah ataupun tidak di waktu tersebut. Paling tidak inilah yang dapat dimengerti, walaupun sebenarnya bisa diluaskan dari itu (Shihab, 2012:419).

Dalam kitab Imam Jalaluddin, Ibnu Ishaq mengatakan, "Ismail bin Khalid memberitahukan kepada saya dari Abu Ishaq dari al-Barra', bahwa ia mengatakan: Dahulu Nabi Saw. shalat mengarah ke Baitul Maqdis. Dikala itu beliau selalu memandang ke arah langit dengan maksud menunggu datangnya wahyu dari Allah.

Surah al-Baqarah [2]: 261

Asbab an-Nuzul ayat ini turun, disebutkan dari sebagian riwayat, mengenai kemurahan hati Utsman bin 'Affan dan Abdurrahman bin 'Auf r.a. datanglah mereka membawa hartanya 
untuk menanggung biaya perang Tabuk. Bahwa ayat ini turun mengenai mereka, bukanlah berarti bahwa ia bukan janji Ilahi kepada setiap orang yang menginfakkan hartaanya dengan tulus (Shihab, 2012:689).

\section{Surah al-Baqarah [2]: 284}

Imam Muslim meriwayatkan, melalui sahabat Rasulullah Saw, Abu Hurairah r.a., bahwa ketika turunnya ayat ini dengan jelas menerangkan Allah akan memperhitungkan kepada semua yang dikerjakan manusia, baik itu anggota tubuh maupun hatinya, secara tersembunyi dan terangterangan, sebagian sahabat mengeluk kepada Rasulullah Saw., dan mengatakan, "Kami telah diberi kewajiban yang tidak sanggup kami tanggung”. Rasullah Saw., berkata, "Apakah kalian akan mengatakan seperti apa perkataan Bani Isra'il, 'Kami mendengar tetaapi kami tidak memperkenanakan? 'Katakanlah, 'Kami mendengarkan, mentaati, berilah kami ampunan (Wahai) Tuhan kami, dan kepada-Mu tempat kembali" (Shihab, 2012:745).

Dari paparan ayat di atas menurut peneliti mengungkapkan sedikitnya asbab an-Nuzul yang terdapat dalam kitab tafsir al-Misbah dikarenakan kitab ini lebih menekankan pada pendekatan bahasa dan memang setiap tulisan pasti mempunyai fokus dan tujuan maupun penulisan kitab tafsir sesuai kondisi seorang mufassir tersebut.

\section{Contoh Penekanan Pendekatan Kebahasaan}

Contoh penafsiran kitab tafsir AlMisbah pada surah al-Baqarah [2] ayat 9 sebagai berikut:

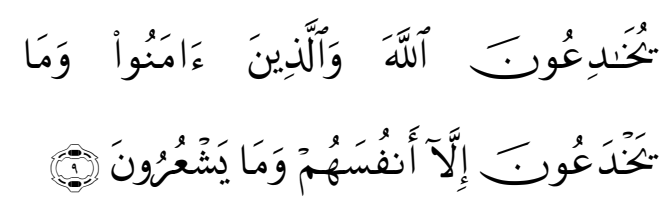

"Mereka membohongi Allah dan orang-orang yang beriman, padahal mereka hanyalah membohongi diri mereka sendiri tanpa mereka sadari".

Kata (يخادعون) yukhadi'una terambil dari kata (خد ع) khada'ayang ialah ucapan atau perbuatan yang disertai dengan pengelabuan seakanakan pelakunya mempunyai maksud baik padahal sebaliknya. Pelaku melakukan hal itu terkadang untuk mengurungkan niat seseorang untuk melakukan sesuatu, sehingga pelaku berbuat suatu hal lain yang lebih menguntungkan pelaku. 
Perlakuan seperti ini tidaklah perasaan yang dinafikan ini ialah pantas dalam situasi apapun terkecuali perasaan yang bersumber dari pada peperangan. Dalam situasi ini, keimanan dan budi pekerti. Dan Rasulullah Saw. berkata: الحر ب خد عة berfungsi memberikan sensibilitas peperangan adalah sebuah aktivitas terhadap lingkugan. Terkadang ada yang dikerjakan bagi orang yang mahir seseorang yang memiliki indra perasa dalam bertipu daya. Adapun yang tetapi dia tidak peka terhadap apapun. memperlihatkan dirinya semacam Apabila itu terjadi janganlah tertipu terhadap yang menipu selama mengharapkan terciptanya akhlak yang sikap ini tidak mendatangkan kerugian baik kepada Allah, makhluk, serta dia terkenal kebaikannya ataupun lingkungan sekitarnya (Shihab, paling tidak saling bertoleransi.

Allah berfirman: (لايشعرون) / tidak 2012:122-123).

Alasan paling mendasar bagi sadar berasal dari kata sya'ura yang artinya merasa. Rasa ialah suatu pengetahuan dan dapat diartikan mengetahui, pengetahuan dimaksudkan mengenai perkara yang diteliti, terselip dan halus. Itulah sebab mengapa penyair dinamai (شاعر) sya'ir peneliti mengenai mengapa M. Quraish sedikit menyajikan asbab an-Nuzul dalam kitab tafsir al-Misbah? Dikarenakan setiap ayat-ayat Alquran yang turun kepada nabi Muhammad Saw itu tidak semestinya ada kausalitas dikarenakan ia memahami arti yang tersembunyi dan menyajikan sajaksajaknya dengan kalimat yang tertata rapi dan indah. Pendapat lain mengatakan bahwa kata ini berasal dari kata (شعار) syi'ar artinya baju yang dipakai seseorang. Dari kata ini terciptalah kata yang menyatakan kepada yang dilahirkan oleh indra pada setiap ayat.Dalam kitab tafsir alMisbah lebih menekankan dengan pendekatan kebahasaan yang menjadi dasar penjelasan dan penafsiran dalam kitab tafsirnyadapat dilihat bahwa beliau tidak menfokuskan pada asbab an-Nuzulnya, bisa jadi asbab an-Nuzul dalam kitab tafsir al-Misbah merupakan pelengkap dalam perasa. Menurut M. Quraish indra juga menyajikan dan membandingkan perasa yang dimaksudkan dengan berbagai pendapat ulama-ulama 
terdahulu dalam kitab tafsirnya, serta disetiap tulisan maupun penafsiran penulis pasti mempunyai pembatasan atau focus kajian dalam menafsirkan Alquran demi mencapai target yang diinginkan oleh penulis dengan artian melihat pada situasi dan kondisi saat beliau menerangkan maksud dari ayatayat Alquran.Dengan tujuan supaya para pembaca mendapatkan wawasan yang lebih luas mengenai apa yang muffasir ingin sampaikan melalui ayat tersebut.

Adapun cara pengutipan asbab anNuzul yang dilakukan oleh M. Quraish Shihab adalah ketika beliau menafsirkan suatu ayat yang terdapat asbab an-Nuzulnya, ada yang menggunakan sanad ada juga tidak bersanad dan tidak secara lengkap pengutipan sanad dalam kitab tafsir alMisbah. Meskipun beliau tidak memberikan keterangan dan rujukan dalam mengutip asbab an-Nuzul dalam kitab tafsir al-Misbah. Tetapi peneliti mencoba langsung merujuk kepada kitab asbab an-Nuzul karangan alImam Abi al-Hasan 'Ali bin Ahmad alWahidi dalam kitabnya Asbab Nuzul Al-Qur'an untuk melakukan pengecekan secara langsung. Pada ayat
190 ini beliau memaparkan ayat ini turun menyangkut perintah perang tetapi beliau tidak memaparkan asbab an-Nuzulnya. Sedangkan pada ayat 222 beliau juga menjelaskan tentang haidnya seorang wanita, dalam penafsiran beliau peneliti menemukan penyatuan asbab an-Nuzul dan penafsiran, dipaparkan dalam kitab asSuyuthi Imam Muslim dan at-Tirmidzi meriwayatkan dari Anas bahwa orangorang Yahudi, ketika istri mereka dalam keadaan haid, mereka tidak memberinya makan dan tidak juga menggaulinya di rumah. Maka para sahabat nabi Saw. menanyakan tentang perkara itu kepada nabi Saw maka turunlah ayat 222 ini (Shihab, 2012:583).

\section{Kegunaan Asbab an-Nuzul dalam Kitab Tafsir al-Misbah}

Adz-Dzarkasyiy berpendapat bahwa asbab an-Nuzul tidak dipentingkan dalam memahami ayatayat Alquran, dan itu merupakan pandangan yang salah (Jabbar, 2014:77).

Kegunaan yang peneliti tangkap dari asbab an-Nuzul dalam kitab tafsir al-Misbah yakni untuk memudahkan dan membantu para pembaca dalam 
memahami suatu ayat pada kitab tafsir. Selain itu beliau memberikan asbab anNuzul supaya para pembaca menelaah asbab an-Nuzul kembali sehingga dari beberapa para pembaca mempunyai ketertarikan untuk langsung merujuk kepada kitab asbab an-Nuzul dengan tujuan menambah khazanah dalam pembelajaran bagi para pembaca. Serta asbab an-Nuzul yang digunakan M. Quraish Shihab sebagai pelengkap untuk para pembaca dan mengetahui yang mana tedapat beberapa asbab anNuzul direlasikan dengan terjemahan dan penafsiran serta memperjelas konteks dari ayat agar pembaca dapat mengetahui peristiwa tersebut dalam artian penting dalam tafsiran. Meskipun beliau tidak memberikan asbab an-Nuzul secara lengkap sesuai kausalitas ayat tetapi beliau tetap menafsirkan Alquran menggunakan asbab an-Nuzul sesuai kebutuhan dalam menafsirkan ayat. Lain halnya ketika beliau tidak setuju dengan adanya disiplin ilmu asbab an-Nuzul yakni cabang dari ilmu ulmul Quran dalam menafsirkan Alquran pastinya beliau tidak menggunakan asbab anNuzul dalam menafsirkan ayat-ayat Alquran.
Dapat diamati bahwa beliau juga ikut menuangkan ide-ide beliau yang berbentuk tulisan mengenai asbab anNuzulbahkan beliau mendefinisikan asbab an-Nuzul Alquran.

\section{KESIMPULAN}

Dalam kitab tafsir al-Misbah M. Quraish Shihab khususnya surah alBaqarah berjumlah 286. Dalam surah ini tidak banyak mewalakkan asbab anNuzul dalam kitab tafsirnya. Asbab anNuzul yang terdapat dalam kitab tafsir al-Misbah ada 7 ayat. Pada setiap ayat yang terdapat dalam Alquran ada tidak semuanya mempunyai asbab an-Nuzul. Dikarenakan setiap ayat-ayat Alquran yang turun kepada Nabi Muhammad Saw itu tidak semestinya ada kausalitas pada ayat tersebut. Dalam penafsiran kitab al-Misbah beliau lebih menekankan penafsirannya dengan pedekatan kebahasaan, di setiap tulisan maupun penafsiran penulis pasti mempunyai pembatasan atau fokus kajian dalam menafsirkan Alquran demi mencapai target yang diinginkan oleh penulis dengan artian melihat pada situasi dan kondisi saat beliau menafsirkan Alquran yakni kitab tafsir al-Misbah. 


\section{REFERENSI}

Ahmad, Rudi Suryadi. 2013. "Asbab Al-Nuzul Dalam Tafsir Pendidikan", Jurnal Pendidikan Agama Islam- Ta'lim, Vol. 11, No. 2.

Al-Baqi, Muhammad Fuad Abd. 1986. alMu'jam al-Mufahras Li Alfadz alQur'an, Kairo: Dar al-Hadits.

Al-Qattan, Manna Khalil. 2013. Studi Ilmu-Ilmu Qur'an, Terj. Mudzakir, Bogor: Pustaka Litera Antar Nusa.

Al-Wahidi, Imam Abi Hasan 'Ali bin Ahmad, T.th. Asbab Nuzul Alquran, Beirut: Lebanon.

--------, 1988. Asbab an-Nuzul, Beirut: Dar al-Fikr.

Anshori. 2006. "Penafsiran Ayat-Ayat Jender Dalam Tafsir AlMisbah", Disertasi, UIN Syarif Hidayatullah: Jakarta.

Arifin, Mochammad. 2019. 10 Tema Fenomenal dalam Ilmu Alquran, Jakarta: Elex Media Komputindo.

Al-Suyuthi, Jalaluddin. 2008. Lubab al-Nuqul fi asbab an-Nuzul, Terj. Abdul Hayyie dkk, Asbabun Nuzul: Sebab Turunnya Ayat al-Qur'an, Jakarta: Gema Insani.

------, 1996. al-Itqan fi 'Ulum alQur'an, Beirut: Muassasah alKitabal Tsaqafah.

Baidan, Nashruddin. 2011. Wawasan Baru Ilmu Tafsir, Yogyakarta: Pustaka Pelajar.

Ghofur, Saiful Amin. 2013. Mozaik Mufasir Alquran dari Klasik hingga Kontemporer, Yogyakarta: Kaukaba.

Jabbar, Luqman Abdul. 2014. 'Ulum al-Qur'an (Metodologi Studi alQur'an), Pontianak: STAIN Pontianak Press.
Muslimah Siti dkk. 2017. "Urgensi Asbab al-Nuzul Menurut alWahidi", Jurnal Al-Bayan: Studi Alquran dan Tafsir, Vol. 2, No. 1.

Nur, Afrizal. 2018. Tafsir Al-Misbah dalam Sorotan (Kritik Terhadap Karya Tafsir Prof. M. Quraish Shihab), Jakarta: Pustaka AlKausar.

Rohani, Fitri. 2018. Akal Sebagai Instrumen Belajar Manusia Dalam Tafsir Al-Misbah, Skripsi, UIN Sumatera Utara Medan.

Saragih, M. Syafi'I. 2015. Memaknai Jihad (Antara Sayyid Quthub \& Quraish Shihab), Yogyakarta: Deepublish.

Shihab, M. Quraish Shihab. 2012. Tafsir Al-Misbah Pesan, Kesan, dan Keserasian al-Qur'an. Jakarta: Lentera Hati.

Suma, Muhammad Amin. 2013. Ulumul Qur'an, Jakarta: Rajawali Pers.

Syafril. 2018. "Asbab Nuzul: Kajian Historis Turunnya Ayat alQur'an", Jurnal Syahadah, Vol. VI, No. 2.

Tamam, Badru. 2008. Corak Pemikiran Kalam Muhammad Quraish Shihab Dalam Tafsir Al-Misbah, Tesis, UIN Syarif Hidayatullah Jakarta.

Wartini, Atik. 2014. "Corak Penafsiran M. Quraish Shihab Dalam Tafsir Al-Misbah", Jurnal KMIP UNY Yogyakarta, Vol. 11, No.1.

Ya'qub, Tahir Mahmud Muhammad. 1425. Asbab al-Khatha'fi alTafsir: Dirasah Ta'siliyah, (alMuklakah) al-Arabiyah alSu'udiyah: Dar Ibn al-Jauzi, J-I, Cet-I. 